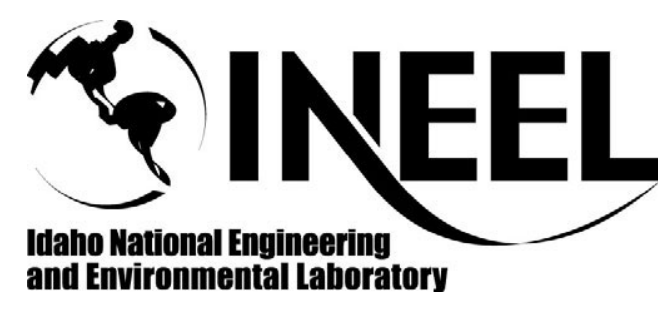

INEEL/CON-03-01375

PREPRINT

Modeling An RF Cold Crucible Induction Heated Melter With Subsidence

Grant Hawkes

July $11-15,2004$

ASME National Heat Transfer Conference

This is a preprint of a paper intended for publication in a journal or proceedings. Since changes may be made before publication, this preprint should not be cited or reproduced without permission of the author.

This document was prepared as a account of work sponsored by an agency of the United States Government. Neither the United States Government nor any agency thereof, or any of their employees, makes any warranty, expressed or implied, or assumes any legal liability or responsibility for any third party's use, or the results of such use, of any information, apparatus, product or process disclosed in this report, or represents that its use by such third party would not infringe privately owned rights. The views expressed in this paper are not necessarily those of the U.S. Government or the sponsoring agency. 


\title{
HT-FED2004-56376
}

\section{MODELING AN RF COLD CRUCIBLE INDUCTION HEATED MELTER WITH SUBSIDENCE}

\author{
Grant Hawkes \\ Idaho National Engineering and Environmental Laboratory (INEEL)
}

\begin{abstract}
A method to reduce radioactive waste volume that includes melting glass in a cold crucible radio frequency induction heated melter has been investigated numerically. The purpose of the study is to correlate the numerical investigation with an experimental apparatus that melts glass in the above mentioned melter. Unique to this model is the subsidence of the glass as it changes from a powder to molten glass and drastically changes density. A model has been created that couples the magnetic vector potential (real and imaginary) to a transient startup of the melting process. This magnetic field is coupled to the mass, momentum, and energy equations that vary with time and position as the melt grows. The coupling occurs with the electrical conductivity of the glass as it rises above the melt temperature of the glass and heat is generated. Natural convection within the molten glass helps determine the shape of the melt as it progresses in time. An electromagnetic force is also implemented that is dependent on the electrical properties and frequency of the coil. This study shows the progression of the melt shape with time along with temperatures, power input, velocities, and magnetic vector potential. Coupled to all of this is a generator that will be used for this lab sized experiment. The coupling with the $60 \mathrm{~kW}$ generator occurs with the impedance of the melt as it progresses and changes with time. A power controller has been implemented that controls the primary coil current depending on the power that is induced into the molten glass region.
\end{abstract}

\section{INTRODUCTION}

The same numerical development is used in this report as Munakata [1]. Unique to this paper is the use of the commercial finite element code FIDAP [2]. FIDAP is used to solve the electromagnetic field, coupled with the mass, momentum, and energy equations. A similar paper on this simulation was presented at the ASME National Heat Transfer Conference in July 2003 [3]. The paper from Reference [3] does not include the subsidence of the melt material. This paper is the culmination of numerical models used to simulate the glass melting in an operating induction melter at the INEEL [4].

The international process for immobilization of highactivity waste from aqueous fuel reprocessing is vitrification. Cold Crucible Induction Melter (CCIM) design is based on inductive coupling of a water-cooled high-frequency electrical coil with the glass, causing eddy-currents that produce heat and mixing. This paper shows the startup transient of the melter that is in operation at the Idaho National Engineering and Environmental Laboratory (INEEL) IEDF building.

Figure 1 is a generic block diagram of a cold crucible induction heated melter system showing the eight major system components. While the ancillary systems are critical to the success of a vitrification process, the focus here is on research and development of the melter itself, including only the crucible, coil, and control system. The cooled crucible and induction coil are two key components of a CCIM system. In their simplest form they consist of a cylindrical single pass heat exchanger surrounded by a linear solenoid inductor. Figure 2 is a photograph of the induction melter located at the INEEL while molten glass is draining out the bottom of the crucible. This melter is 12 -inches in diameter and 20 -inches tall. Note that both the crucible and the induction coil are cylindrical.

The crucible contains the melt material. In a CCIM system the crucible consists of cooled sections, closely spaced, but not touching, configured such that a wall around an internal volume is created. The container can be a simple circular rightcylinder, oval, rectangular, or a more complex shape such a cruciform. The vertical stainless steel tubes forming the walls of the crucible in the photograph are parallel cooling loops fed by the stainless steel ring manifold that acts as a supporting base for the crucible. The hairpin cooling loops can be considered similar to the staves of a wooden barrel. The loops do not touch, but are sufficiently close that the cooling they provide maintains a frozen layer of glass lining and effectively sealing the crucible. Because the cooling loops do not touch, they cannot conduct current around the crucible, and are essentially transparent to the induced field. Thus, the inductive 
field generated by the surrounding coil passes through the crucible wall and interacts with the crucible contents. The cooling tubes do absorb some of the energy that is meant to go into the melt because they are electrically conductive. The magnetic field does penetrate through the slits in the crucible and induces heat in the melt material. It is important that there is no circumferential conductive path in the crucible. If such a path exists, much of the heat would be generated in this area and would melt the crucible and heat would not be deposited in the intended melt material.

\section{MODEL DESCRIPTION}

The purpose of this model is to deterministically assess the transient startup of a melt configuration shown in Figure 3. This model is an (r-z) model (axi-symmetric). Six turns of a 3/8-in copper coil tube are used as the primary coil current source. The crucible is not included in this model. This is an admitted shortcoming as heat is deposited into the crucible, but a 3-D model would be needed to allow for the crucible tubes. Russian modelers of CCIM systems [5] estimate this to be about $18 \%$ of the deposited heat. The heat induced into the melt is reduced by $18 \%$ to account for this. A boundary temperature of $290 \mathrm{~K}$ is assumed where the water-cooled crucible is. Radiation heat transfer from surface to surface is assumed in the air above the melt. A hood is assumed at the top of the model, which simulates the off-gas system. Convective heat transfer is assumed on the outside of the hood. The watercooled tubes extend approximately $150 \mathrm{~mm}$ above the melt material. The top of the hood is $300 \mathrm{~mm}$ above the melt material. The computational domain is extended to $+/-700 \mathrm{~mm}$ in the axial direction, and $1000 \mathrm{~mm}$ in the radial direction.

A ring of a conductive material $(1000 \mathrm{~S} / \mathrm{m})$ is used for the first 600 seconds of simulation. This is where the heat is generated until the glass reaches a temperature high enough to generate heat. After 600 seconds, the electrical conductivity of the material in the ring switches over to the electrical properties of glass for the remainder of the simulation. Running the simulation several times and adjusting this parameter found the time of 600 seconds. If a shorter time were used, then the melt would cool off and die and become the water temperature. In reality, a highly conductive material is placed in the melters for startup. The starter material gets consumed and mixed with the glass after convection starts.

Included in this model is natural convection of the glass as it is simulated in time. The melt grows and Navier-Stokes equations are solved for the convection within the melt that is driven by density differences. The heat transfer coefficient of $5.0 \mathrm{~W} / \mathrm{m}^{2}-\mathrm{K}$ on the outside of the hood area was chosen as a typical natural convection heat transfer coefficient. The model could have included an $\mathrm{h}$ that varies with temperature, but was not done so as to concentrate the work on the melting of the glass.

A power controller is implemented in this model. The primary coil current is adjusted until the desired power is met. For this model, a power of $60 \mathrm{~kW}$ of induced heat is desired into the glass melt. A $60 \mathrm{~kW}$ generator is used in the laboratory experiment [4]. A limit on the current is set at $70 \mathrm{Amps}$ rms. The power is calculated with the FIDAP post processor and the current is adjusted at the next time interval by the ratio of the square root of the desired power versus actual power. Simply it is a proportional power controller. We admit that this has several shortcomings and does not take into account the leakage inductance. We do plan to implement a power controller in the future that takes into account the leakage inductance, the primary coil inductance, open circuit voltage of the generator, primary lead impedance, and melt resistance. This model simply shows that we can control the power in the melt by controlling the current and that it adjusts itself on the fly due to the changing melt volume and resistance of the melt.

\section{NOMENCLATURE}

$\begin{array}{ll}\boldsymbol{A} & \text { vector potential, } \mathrm{m}-\mathrm{T} \\ \boldsymbol{B} & \text { magnetic flux density, } \mathrm{T} \\ \mathrm{c}_{\mathrm{p}} & \text { specific heat, } \mathrm{J} / \mathrm{kg}-\mathrm{K} \\ \boldsymbol{E} & \text { electric field intensity, } \mathrm{V} / \mathrm{m} \\ \boldsymbol{f}_{\boldsymbol{e}} & \text { RF-induced electromagnetic force density, } \mathrm{N} / \mathrm{m}^{3} \\ \boldsymbol{g} & \text { gravitational acceleration, } \mathrm{m} / \mathrm{s}^{2} \\ \mathrm{~h} & \text { heat transfer coefficient, } \mathrm{W} / \mathrm{m}^{2}-\mathrm{K} \\ \boldsymbol{I} & \text { overall electric current density }=\boldsymbol{J}+\boldsymbol{j} \\ I_{\text {new }} & \text { primary coil current for new time step, A } \\ I_{\text {old }} & \text { primary coil current for previous time step, A } \\ \boldsymbol{J} & \text { coil electric current density, A/m } \mathrm{m}^{2} \\ \boldsymbol{j} & \mathrm{RF} \text { induced electric current density, A } / \mathrm{m}^{2} \\ \mathrm{k} & \text { thermal conductivity, } \mathrm{W} / \mathrm{m}-\mathrm{K} \\ \mathrm{p} & \text { pressure, Pa } \\ P_{d} & \text { desired power induced into melt, } \mathrm{W} \\ P_{\text {calc }} & \text { calculated power induced into melt, } \mathrm{W} \\ Q_{\mathrm{e}} & \text { RF-induced heat generation density, } \mathrm{W} / \mathrm{m}^{3} \\ \mathrm{r}, \mathrm{Z} & \text { coordinate } \\ \mathrm{T} & \text { temperature, } \mathrm{K} \\ T_{\text {ref }} & \text { reference temperature for buoyancy calculation, } \mathrm{K} \\ T_{\text {wall }} & \text { wall temperature of hood, } \mathrm{K} \\ T_{\infty} & \text { environment temperature, } \mathrm{K} \\ \mathrm{t} & \text { time, } \mathrm{s} \\ \boldsymbol{u} & \text { velocity vector, m/s } \\ V & \text { volume of each finite element }\end{array}$

\section{Greek letters}

$\beta_{T} \quad$ volumetric expansion coefficient, $1 / \mathrm{K}$

$\varepsilon \quad$ emissivity

$\phi \quad$ modified vector potential with respect to azimuthal component, $\mathrm{m}^{2}-\mathrm{T}$

$\mu \quad$ dynamic viscosity, $\mathrm{kg} / \mathrm{m}-\mathrm{s}$

$\mu_{e} \quad$ permeability, $\mathrm{H} / \mathrm{m}$

$\rho$ density, $\mathrm{kg} / \mathrm{m}^{3}$

$\sigma_{e} \quad$ electrical conductivity, $\mathrm{S} / \mathrm{m}$

$\sigma_{S B} \quad$ Stefan-Boltzmann constant, $\mathrm{W} / \mathrm{m}^{2}-\mathrm{K}^{4}$

$\sigma_{r, \theta, z}$ stress notation in momentum equation, $\mathrm{Pa}$ 
$\omega_{e} \quad$ angular frequency, $\mathrm{rad} / \mathrm{s}$

\section{Subscript}

$c, s \quad$ cosine and sine component

$r, \theta, z$ coordinate direction component

\section{NUMERICAL FORMULATION}

As shown in Figure 3, the main assumptions, which are used here, are as follows. (1) The system is axi-symmetric. (2) The induction coil is a six-turn coil (top six of nine turns are used in this simulation) with annular cross section. (3) An AC current is applied to the induction coil. (4) Natural convection within the melt is considered. Details of the numerical formulation are as follows.

\section{$R F$ induced electromagnetic field}

From Maxwell's equations, if the effect of convection could be neglected, we have the following equations:

$$
\begin{gathered}
\nabla \times \mathbf{B}=\mu_{e} \mathbf{I} \\
\nabla \times \mathbf{E}=-\frac{\partial \mathbf{B}}{\partial t} \\
\mathbf{I}=\sigma_{e} \mathbf{E} \\
\nabla \cdot \mathbf{B}=0 \\
\nabla \cdot \mathbf{E}=0
\end{gathered}
$$

By introducing a magnetic vector potential $\boldsymbol{A}$ and Coulomb gauge such that

$$
\begin{gathered}
\mathbf{B}=\nabla \times \mathbf{A}, \text { and } \\
\nabla \cdot \mathbf{A}=0
\end{gathered}
$$

Equation 6 in axi-symmetric form is taken as

$$
\begin{gathered}
\nabla \times \mathbf{A}=\frac{1}{r}\left|\begin{array}{ccc}
\mathbf{a}_{r} & \mathbf{a}_{\theta} r & \mathbf{a}_{z} \\
\frac{\partial}{\partial r} & \frac{\partial}{\partial \theta} & \frac{\partial}{\partial z} \\
\mathbf{A}_{r} & r \mathbf{A}_{\theta} & \mathbf{A}_{z}
\end{array}\right| \text {,and } \\
\nabla \times \nabla \times \mathbf{A}=\frac{1}{r}\left|\begin{array}{ccc}
\mathbf{a}_{r} & \mathbf{a}_{\theta} r & \mathbf{a}_{z} \\
\frac{\partial}{\partial r} & \frac{\partial}{\partial \theta} & \frac{\partial}{\partial z} \\
-\frac{\partial A_{\theta}}{\partial z} & 0 & \left(\frac{\partial A_{\theta}}{\partial r}+\frac{A_{\theta}}{r}\right.
\end{array}\right|
\end{gathered}
$$

By expanding this determinant out and eliminating all derivatives of $A_{r}$ and $A_{z}$, one comes up with the following equation:

$$
\frac{\partial^{2} A_{\theta}}{\partial r^{2}}+\frac{1}{r} \frac{\partial A_{\theta}}{\partial r}+\frac{\partial^{2} A_{\theta}}{\partial z^{2}}-\frac{A_{\theta}}{r^{2}}=-\mu_{e} \mathbf{I}
$$

where $A_{\theta}$ is the azimuthal component of the magnetic vector potential A. By introducing a new variable $\phi$ named the modified vector potential where $\phi=r A_{\theta}$. After expanding Eq. 10 , the following equation is obtained for $\phi$.

$$
\frac{\partial}{\partial r}\left(\frac{1}{r} \frac{\partial \phi}{\partial r}\right)+\frac{\partial}{\partial z}\left(\frac{1}{r} \frac{\partial \phi}{\partial z}\right)=-\mu_{e} I_{\theta}
$$

Note that Eq. (11) appears as a 2-D diffusion equation where the diffusivity term appears to be $\left(\frac{1}{r}\right)$. This is what is unique about this paper. The commercial CFD code FIDAP is used to solve this magnetic vector potential equation as a 2-D diffusion equation and use the magnetic vector potentials as a heat source for the axi-symmetric energy equation. Setting the diffusivity in equation 11 to be $1 / \mathrm{r}$ does this. It must be noted that these magnetic vector potentials are amplitudes and not rms values. The modified vector potential is expressed as follows:

$$
\phi=\phi_{c} \cos \left(\omega_{e} t\right)+\phi_{s} \sin \left(\omega_{e} t\right)
$$

By substituting Eq. (12) into Eq. (11) and using the relations of Eqs. (2) and (3), the following equations are obtained:

$$
\frac{\partial^{2} \phi_{c}}{\partial r^{2}}+\frac{\partial^{2} \phi_{c}}{\partial z^{2}}-\frac{1}{r} \frac{\partial \phi_{c}}{\partial r}=\mu_{e} \sigma_{e} \omega_{e} \phi_{s}
$$

$$
\frac{\partial^{2} \phi_{s}}{\partial r^{2}}+\frac{\partial^{2} \phi_{s}}{\partial z^{2}}-\frac{1}{r} \frac{\partial \phi_{s}}{\partial r}=-\mu_{e}\left(r J_{\theta}+\sigma_{e} \omega_{e} \phi_{c}\right)
$$

Where $J$ is the current source term. These equations are implemented in FIDAP by setting the source term in the FIDAP subroutine as follows:

Coil: $\quad 0$ for Eq. 13

$$
\mu_{e} J_{\theta} \text { for Eq. } 14
$$

Glass: $\frac{-\mu_{e} \sigma_{e} \omega_{e} \phi_{s}}{r} \quad$ for Eq. 13

$$
\frac{\mu_{e} \sigma_{e} \omega_{e} \phi_{c}}{r} \quad \text { for Eq. } 14
$$




\section{Air/space: $\quad 0$ for Eq. 13 and 14}

From Equation 11 of Reference [1], the RF-induced average heat generation rate is

$$
Q_{e}=\frac{\sigma_{e} \omega_{e}^{2}}{2 r^{2}}\left(\phi_{c}^{2}+\phi_{s}^{2}\right)
$$

Also from Reference [1], the electromagnetic force $f_{\mathrm{e}}$ which affects the melt motion is defined as $\boldsymbol{j} \times \boldsymbol{B}$. In axi-symmetric coordinates, the time-averaged electromagnetic force is expressed as follows:

$$
\begin{gathered}
f_{e r}=\frac{\sigma_{e} \omega_{e}}{2 r^{2}}\left(\phi_{c} \frac{\partial \phi_{s}}{\partial r}-\phi_{s} \frac{\partial \phi_{c}}{\partial r}\right) \\
f_{e z}=\frac{\sigma_{e} \omega_{e}}{2 r^{2}}\left(\phi_{c} \frac{\partial \phi_{s}}{\partial z}-\phi_{s} \frac{\partial \phi_{c}}{\partial z}\right)
\end{gathered}
$$

where $f_{\mathrm{er}}$ and $f_{\mathrm{ez}}$ are the RF induced $\mathrm{r}$ - and $\mathrm{z}$-direction electromagnetic forces, respectively. Eq. 16 and 17 will be coupled with the momentum equations as a body force within FIDAP.

\section{Exact comparison with FIDAP for electromagnetic equations}

When Eq. 11 is expanded, it becomes:

$$
\frac{1}{r} \frac{\partial^{2} \phi}{\partial r^{2}}-\frac{1}{r^{2}} \frac{\partial \phi}{\partial r}+\frac{1}{r} \frac{\partial^{2} \phi}{\partial z^{2}}=-\mu_{e} I_{\theta}
$$

An arbitrary function of $\phi$ was chosen as:

$$
\phi=r^{5}+z^{5}
$$

When solving for Eq. 19 in the form of Eq. 18 yields:

$$
\frac{1}{r} \frac{\partial^{2} \phi}{\partial r^{2}}-\frac{1}{r^{2}} \frac{\partial \phi}{\partial r}+\frac{1}{r} \frac{\partial^{2} \phi}{\partial z^{2}}=15 r^{2}+20 \frac{z^{3}}{r}
$$

with a computational domain of $0 \leq r \leq 1,0 \leq z \leq 1$ and with boundary conditions that satisfy Eq. 19 along the boundaries. Using these boundary conditions and solving the problem with FIDAP as a steady-state 2-D problem, and setting the species diffusivity $=1 / \mathrm{r}$, the FIDAP results and the exact solution of Eq. 19 were compared along lines at $z=0.5$ and at $r$ $=0.5$. The FIDAP results were within $1 \mathrm{e}-5$ of the exact solution. This gives us the use of FIDAP to solve Eqs. 13 and 14 with the same technique of setting the diffusivity to $1 / \mathrm{r}$ and solving a 2-D diffusion problem.

\section{Governing equations}

The governing equations of transient natural convection are given by:

Continuity: $\quad \frac{1}{r} \frac{\partial}{\partial r}\left(\rho r u_{r}\right)+\frac{\partial}{\partial z}\left(\rho u_{z}\right)=0$

R-Momentum:

$$
\rho\left(\frac{\partial u_{r}}{\partial t}+u_{r} \frac{\partial u_{r}}{\partial r}+u_{z} \frac{\partial u_{r}}{\partial z}\right)
$$

$$
=\frac{1}{r} \frac{\partial}{\partial r}\left(r \sigma_{r r}\right)-\frac{1}{r} \sigma_{\theta \theta}+\frac{\partial \sigma_{r z}}{\partial z}+f_{e r}
$$

Z-Momentum:

$$
\begin{gathered}
\rho\left(\frac{\partial u_{z}}{\partial t}+u_{r} \frac{\partial u_{z}}{\partial r}+u_{z} \frac{\partial u_{z}}{\partial z}\right) \\
=\frac{1}{r} \frac{\partial}{\partial r}\left(r \sigma_{r z}\right)-\frac{1}{r} \sigma_{\theta \theta}+\frac{\partial \sigma_{z z}}{\partial z}+\rho g \beta_{T}\left(T-T_{r e f}\right)+f_{e z} \\
\sigma_{r r}=-p+2 \mu(T) \frac{\partial u_{r}}{\partial r} \sigma_{\theta \theta}=-p+2 \mu(T) \frac{u_{r}}{r} \\
\sigma_{r z}=\mu(T)\left(\frac{\partial u_{r}}{\partial z}+\frac{\partial u_{z}}{\partial r}\right) \sigma_{z z}=-p+2 \mu(T) \frac{\partial u_{z}}{\partial z}
\end{gathered}
$$

Energy:

$$
\rho c_{p}\left(\frac{\partial T}{\partial t}+u_{r} \frac{\partial T}{\partial r}+u_{z} \frac{\partial T}{\partial z}\right)
$$

$$
=k(T)\left(\frac{\partial^{2} T}{\partial r^{2}}+\frac{\partial^{2} T}{\partial z^{2}}+\frac{1}{r} \frac{\partial T}{\partial r}\right)+Q_{e}
$$

\section{Boundary conditions}

(a) At the computational domain boundaries

$$
\phi_{c}=0, \quad \phi_{s}=0
$$

(b) At glass/air interface

$$
V z=0, V r=\text { free }
$$

(c) At the center $(\mathrm{r}=0)$

$$
\frac{\partial T}{\partial r}=0, \phi_{c}=0, \quad \phi_{s}=0
$$

(d) Gray body radiation from surface to surface in the enclosed air space at the top of the model. Heat flux boundary conditions as described in FIDAP theory manual. Calculated at start of each heat transfer transient. 
(e) Convective heat transfer on outside of hood

$$
q=h A\left(T_{\text {wall }}-T_{\infty}\right)
$$

\section{Material properties}

The material selected as the melt material is Defense Waste Processing Facility (DWPF) startup frit from Pacific Northwest National Laboratory. The properties are fairly well known up to about $1400 \mathrm{~K}$. Most of the calculations for the melted glass are between 1500-1800 K. Since the properties are not known above $1500 \mathrm{~K}$, we used our best estimation of what they might be and have concurrence with our Russian colleagues from Reference [5]. Table 1 shows the material properties used. Latent heat of fusion for the glass frit was not considered in this analysis. This assumption was made since the latent heat of fusion is so small for glass, meaning that it is less than $3 \%$ of the enthalpy change from room temperature up to $1500 \mathrm{~K}$. Linear interpolation is assumed between the values that are shown.

Table 1. Material properties for glass frit melt material.

$\mu_{\mathrm{e}}=1.257 \mathrm{e}-6 \mathrm{H} / \mathrm{m}$

$\mathrm{T}_{\text {ref }}=290 \mathrm{~K}$

$\rho_{0}=1300 \mathrm{~kg} / \mathrm{m}^{3}$ where $\rho=\rho_{0}\left[1-\beta_{T}\left(T-T_{r e f}\right)\right]$

\begin{tabular}{|c|c|c|c|c|c|}
\hline $\begin{array}{c}\text { Temp } \\
(\mathrm{K})\end{array}$ & $\begin{array}{c}\sigma_{\mathrm{e}} \\
(\mathrm{S} / \mathrm{m})\end{array}$ & $\begin{array}{c}\mu \\
(\mathrm{kg} / \mathrm{m}- \\
\mathrm{s})\end{array}$ & $\begin{array}{c}\mathrm{c}_{\mathrm{p}} \\
(\mathrm{J} / \mathrm{kg}- \\
\mathrm{K})\end{array}$ & $\begin{array}{c}\mathrm{k} \\
(\mathrm{W} / \mathrm{m}-\end{array}$ & $\begin{array}{c}\beta_{\mathrm{T}} \\
(1 / \mathrm{K})\end{array}$ \\
\hline 290 & 0.001 & $1.6 \mathrm{e} 9$ & 696 & 0.813 & 0.0 \\
\hline 373 & & & 757 & & $-4.42 \mathrm{E}-06$ \\
\hline 573 & & & 983 & & $-3.53 \mathrm{E}-05$ \\
\hline 773 & & $1.6 \mathrm{e} 9$ & 1180 & & $-2.12 \mathrm{E}-05$ \\
\hline 973 & & 5455 & 1710 & & $-2.30 \mathrm{E}-05$ \\
\hline 1073 & 0.001 & 376.5 & & & $-3.48 \mathrm{E}-05$ \\
\hline 1173 & 3.333 & 61.59 & & & $-3.22 \mathrm{E}-04$ \\
\hline 1223 & 4.75 & 30.51 & & & $-5.19 \mathrm{E}-04$ \\
\hline 1273 & 6.63 & 16.66 & & & $-6.69 \mathrm{E}-04$ \\
\hline 1323 & 9.14 & 9.84 & & & $-6.50 \mathrm{E}-04$ \\
\hline 1373 & 12.45 & 6.20 & & 1.0 & $-6.31 \mathrm{E}-04$ \\
\hline 1423 & 16.77 & 4.12 & & & $-6.10 \mathrm{E}-04$ \\
\hline 1473 & 19.41 & 2.86 & & 2.0 & $-5.89 \mathrm{E}-04$ \\
\hline 1573 & 24.68 & 1.54 & & & $-5.46 \mathrm{E}-04$ \\
\hline 1673 & 29.96 & 0.92 & & & $-5.04 \mathrm{E}-04$ \\
\hline 1773 & 35.24 & 0.60 & & & $-4.62 \mathrm{E}-04$ \\
\hline 1873 & 40.52 & 0.42 & & & $-4.29 \mathrm{E}-04$ \\
\hline 1973 & 45.80 & 0.31 & & 18.36 & $-4.02 \mathrm{E}-04$ \\
\hline 3000 & 100.0 & 0.31 & 1710 & 39.69 & $-2.57 \mathrm{E}-04$ \\
\hline
\end{tabular}

Initial conductive region: all properties are same as glass, except $\sigma_{\mathrm{e}}=1000 \mathrm{~S} / \mathrm{m}$ for first 600 seconds.

Air properties $\mathrm{k}=0.1 \mathrm{~W} / \mathrm{m}-\mathrm{K}$ (estimated from mixed convection in enclosure based on equivalent conductivity theory, updated each timestep)

$\rho=1.0 \mathrm{~kg} / \mathrm{m}^{3}$

$\mathrm{c}_{\mathrm{p}}=1005 \mathrm{~J} / \mathrm{kg}-\mathrm{K}$

\section{NUMERICAL PROCEDURE}

The governing equations were solved with the commercial CFD code FIDAP. At time equal to zero and the temperature field initialized at $290 \mathrm{~K}$, Eqs 13 and 14 were simultaneously solved over the domain for the real and imaginary portion of the modified magnetic vector potential. This was done in a separate problem of FIDAP and solved as a 2-D problem. An initial primary coil current of 59 Amps (rms) was guessed at time equal to zero. After convergence, the FIDAP post processor was used to calculate the power input into the melt region. The $\phi_{\mathrm{c}}$ and $\phi_{\mathrm{s}}$ were then used in Eq. 15 that is used as the heat source for axi-symmetric Eq. 25. The transient heat transfer and fluid flow calculation then proceeded for a period of five seconds and then stopped. The power controller was then implemented by introducing a new current source into the next time-step of the electromagnetic equations. The new primary coil current was controlled with a proportional controller as

$$
I_{\text {new }}=I_{\text {old }} \sqrt{\frac{P_{d}}{P_{\text {calc }}}}
$$

Where

$$
P_{\text {calc }}=\sum_{i=1}^{N}\left(Q_{e}\right)_{i} V_{i}
$$

Where $Q_{e}$ is the heat source from Eq. 15 and $V$ is the volume of each finite element. The current was limited to not exceed 70 Amps. With this new current, the temperatures at the end of the five second heat transfer calculation were used to calculate a new electromagnetic field. The electrical conductivity corresponding to these temperatures were used in Eqs. 13 and 14 and solved as a steady state problem. After convergence, the $\phi_{\mathrm{c}}$ and $\phi_{\mathrm{s}}$ were fed into the transient heat transfer as a heat source and the calculations proceeded from five seconds to 10 seconds. This process was repeated for until the time reached 3600 seconds. The time period for each calculation was 1.05 times larger than the time before. In short, the heat source remained constant during each transient heat transfer calculational period, and was then updated the next period as the melt grew and the electrical conductivity of the glass changed with time and position. The size and location of the initial conductive region was arrived at by several iterations that would allow the melt to continue to grow and not cool down and die. The results of these calculations will be shown in the Results section. 
For the simulations described within this paper, two to three iterations were required to obtain convergence at each time step for the heat transfer and fluid flow calculations. Approximately 20 iterations were required for the electromagnetic field calculations with a high degree of relaxation.

Subsidence is calculated based on the assumption that the mass in each column of elements remains constant. The density versus temperature curve for the glass frit is shown in Figure 4. In order to calculate the new volume of each column of elements the following equation was used based on the conservation of mass in each column.

$V_{\text {new }}=\frac{(\rho V)_{0}}{\rho_{\text {new }}}$

\section{RESULTS AND DISCUSSION}

Heat transport and melting due to induction heating for a glass frit in a CCIM have been performed for a transient startup for 3600 seconds. Energy was only supplied to the top coil for this simulation. In future studies, the bottom coil will be energized after this time in order to melt the mushy region along the bottom floor of the crucible. The numerical results are shown in Figures 5 through 12. Similar results without the subsidence are shown in the author's previous paper Reference [3].

Figure 5 shows the finite element mesh for the entire domain. There are 8400 four-noded quadrilateral elements in the mesh. A grid independence study was performed where twice as many elements in the $r$ and $z$ direction were used. The temperature and magnetic vector potential values were within $1 \%$, therefore the more coarse mesh was used. Figures 6 and 7 show the imaginary and real modified magnetic vector potential at time $=0$. These figures are the contour plots of Equations 14 and 13 respectively. Notice that the high conductive region acts as a negative source as shown in Eq. 13. This region is shown as the blue area in Figure 7 and as a small island of blue in Figure 6. The coils are shown in Figure 6 as the red areas since they are a current source.

Figure 8 shows the deformed finite element mesh at a time of 100 seconds. The nodes slide down each spine when the density of the glass increases after melting in the initial conductive region.

Shown in Figure 9 are temperature contour plots of the deformed mesh with time. Temperatures above $1800 \mathrm{~K}$ are colored red and the minimum temperature color of blue is at $300 \mathrm{~K}$. Because of the natural convection within the molten region, the hot region grows upward and inward until the top surface subsides to the molten region. After this time, the hot region starts to grow downward. Remember that only the top six of the nine coils are energized for this simulation. The times shown in Figure 9 are at 100, 200, 400, 800, 1200, 1600, 2000, 2400, 3000, and 3600 seconds.
Figure 10 shows the heat generation rate $\left(\mathrm{W} / \mathrm{m}^{3}\right)$ of the glass region with the deformed mesh at the same times as Figure 9. The red contours are at $25 \mathrm{MW} / \mathrm{m}^{3}$. The power induced into the melt and primary coil current histories are shown in Figure 11. The power starts at $29 \mathrm{~kW}$ and the current is adjusted according to Equation 30 for the next time step. The desired power is $60 \mathrm{~kW}$. The controller is quite erratic for the first 600 seconds while the conductive region is still there, but settles down and stays right at $60 \mathrm{~kW}$ from 600 to 3600 seconds. The power has a big drop right after 600 seconds when the conductive region changes to glass frit. The current does just as expected from 600 to 3600 and slowly increases as the resistance of the molten region goes down as the melt grows, thus requiring more current to maintain the power constant.

Figure 12 shows the velocity vectors at the same times as in Figures 9 and 10. A contour line of $1373 \mathrm{~K}$ is plotted in each Figure to show the melt boundary. The maximum velocity plotted in each caption in the figure is as follows $(\mathrm{m} / \mathrm{s})$ :

$\begin{array}{llll}100 \mathrm{~s} & 0.72 \mathrm{e}-3 & 200 \mathrm{~s} & 0.15 \mathrm{e}-2 \\ 400 \mathrm{~s} & 0.21 \mathrm{e}-2 & 800 \mathrm{~s} & 0.26 \mathrm{e}-2 \\ 1200 \mathrm{~s} & 0.46 \mathrm{e}-2 & 1600 \mathrm{~s} & 0.59 \mathrm{e}-2 \\ 2000 \mathrm{~s} & 0.19 \mathrm{e}-1 & 2400 \mathrm{~s} & 0.15 \mathrm{e}-1 \\ 3000 \mathrm{~s} & 0.17 \mathrm{e}-1 & 3600 \mathrm{~s} & 0.17 \mathrm{e}-1\end{array}$

As discussed in Reference [3], there exist two convective cells with the heat rising in the middle and cooling along the outside where the water is. The inner cell cools flowing downward along the colder unmelted region in the center. After the subsidence has occurred, there are still two convective cells with the highest velocity flowing downward at the model centerline.

Figure 13 shows the history of the molten glass volume and the total frit and molten glass volume. At the end of 3600 seconds, it appears that the melt has reached a quasi-steady state and is not progressing downwards. Future analyses will include energizing the bottom six coil turns and melting the bottom of the glass and get it ready to drain out. The first successful experiment of the newly constructed induction melter was conducted on $9 / 24 / 2003$ at the INEEL. From an observation point of view with the subsidence shape and history, these results agree very well with the experimental results observed. The only qualitative measurements taken during this experiment were visual. The melt shape and subsidence took place around the outside and above the starter material. This model suggests the same.

\section{CONCLUSIONS}

A transient startup of a CCIM has been simulated for a time of 3600 seconds with subsidence. Heat transport with natural convection melting was tracked with time with the commercial CFD code FIDAP. Two electromagnetic equations for the real and imaginary magnetic vector potentials were solved with FIDAP and used as an induced heat source into the melt material. The melt grew until all of the glass frit was melted. 
A power controller was implemented by controlling the primary coil current with a proportional controller. Numerical results presented here agree very well with experimental observation results. Only visual results were available from the actual experiment.

\section{ACKNOWLEDGMENTS}

This work was sponsored by the U.S. Department of Energy. The Idaho National Engineering and Environmental Laboratory is operated by Bechtel, Babcock and Wilcox Idaho, LLC under contract number DE-AC07-99ID13727.

\section{REFERENCES}

1. Tetsuo Munakata, Ichiro Tanasawa, "Study on silicon melt convection during the RF-FZ crystal growth process II. numerical investigation", Journal of Crystal Growth, 206 (1999) 27-36.

2. "FIDAP Theory Manual version 8.7.2", Fluent Inc., Lebanon, New Hampshire.

3. Grant Hawkes, et. al. "Heat Transfer Model For an RF Cold Crucible Induction Heated Melter", paper \# HT2003-47397, ASME Summer Heat Transfer Conference, July 21-23, 2003 Las Vegas, Nevada

4. Dirk Gombert, et.al., "Alternative Waste Stabilization Technologies," Environmental Systems Research and Analysis FY 2003 Annual Report, February 2004, INEEL/EXT-03-01217, p. 251.

5. Dmitry Lopukh, "Process Research and Development of Equipment for the Solidification of Radioactive Waste Simulators by Induction Cold Crucible Melting", January 2003, Leningrad Electrotechnical Institute, Russia. 


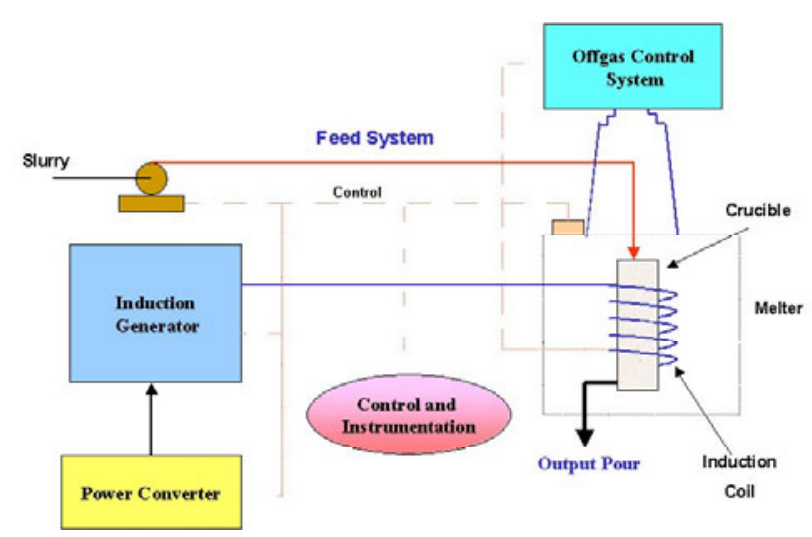

Figure 1. Schematic of CCIM system.

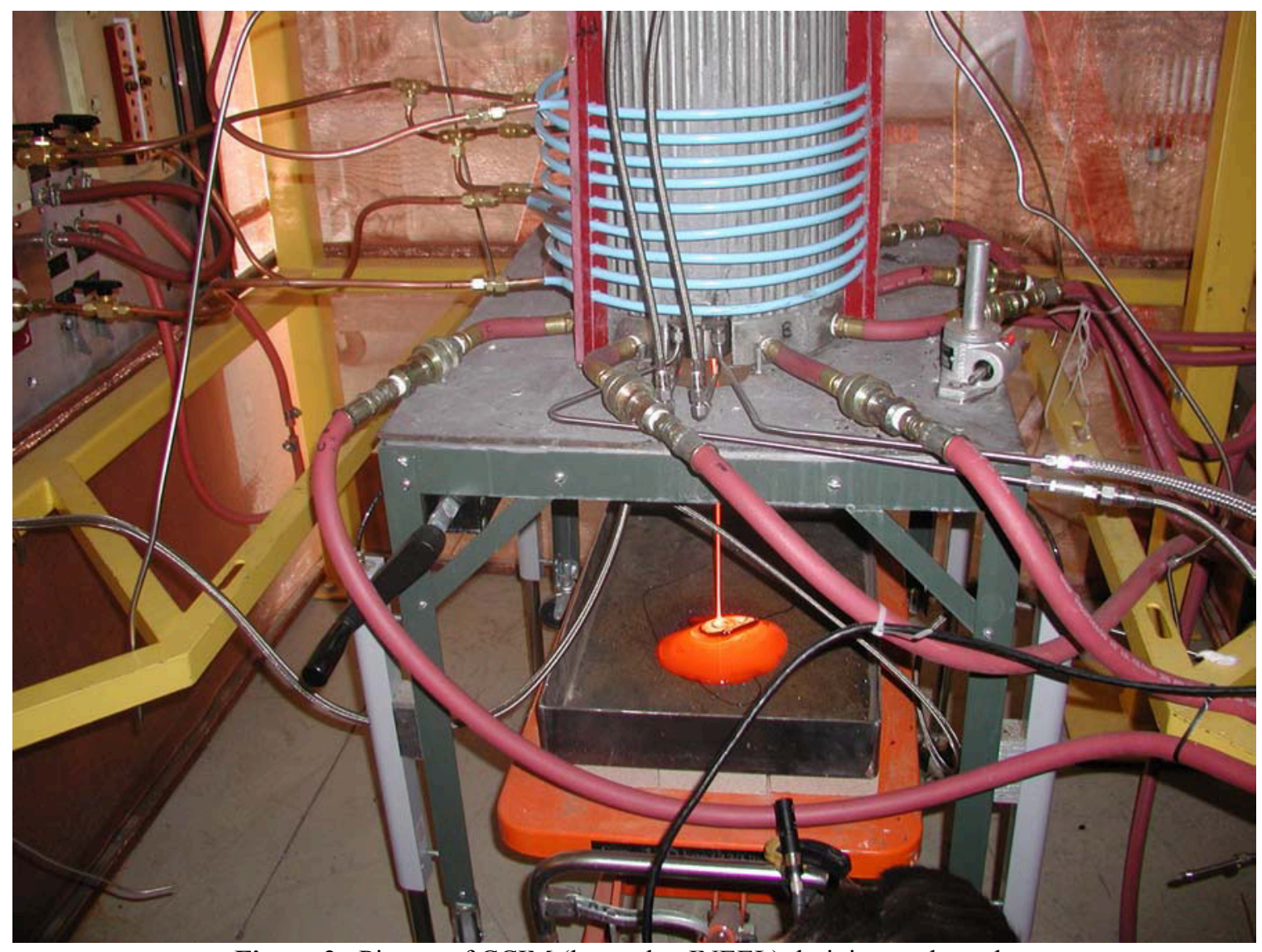

Figure 2. Picture of CCIM (located at INEEL) draining molten glass. 


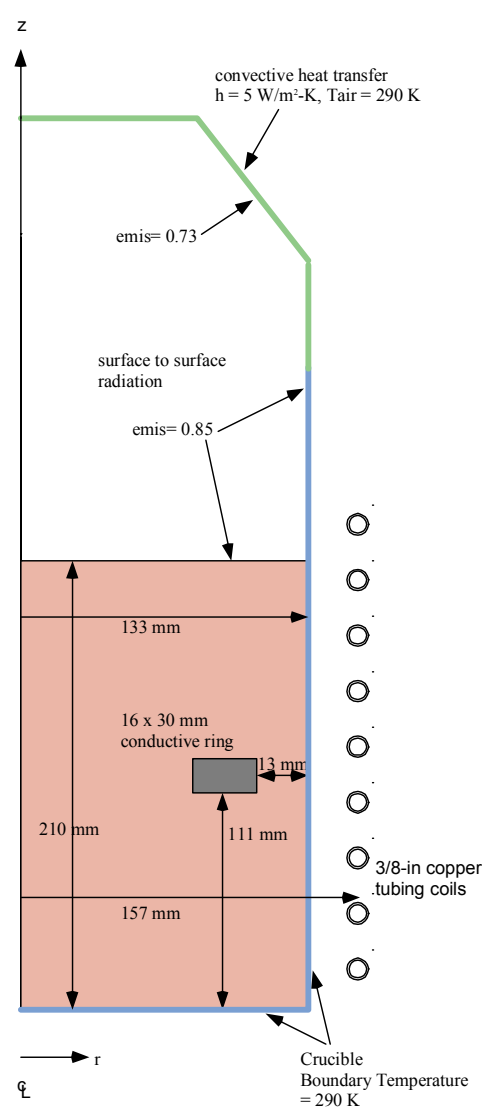

Figure 3. Model description.

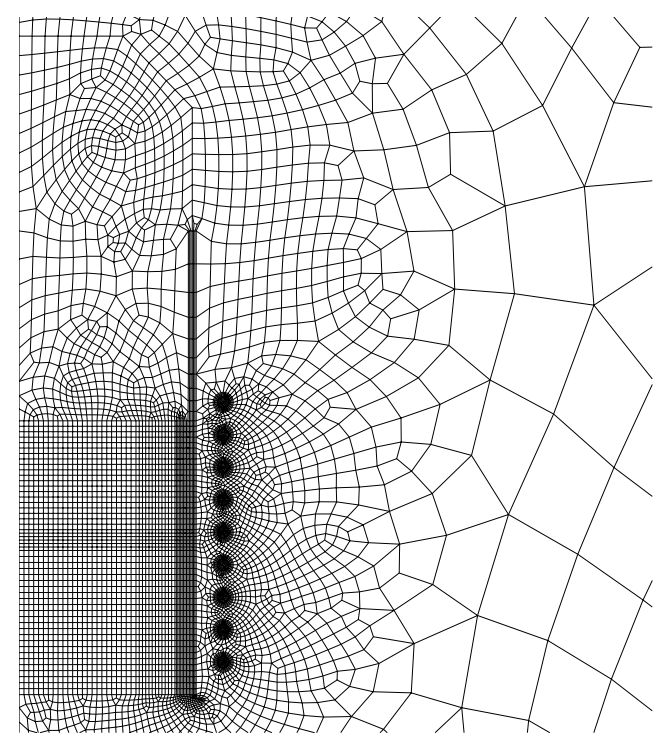

Figure 5. Finite element mesh of entire domain.

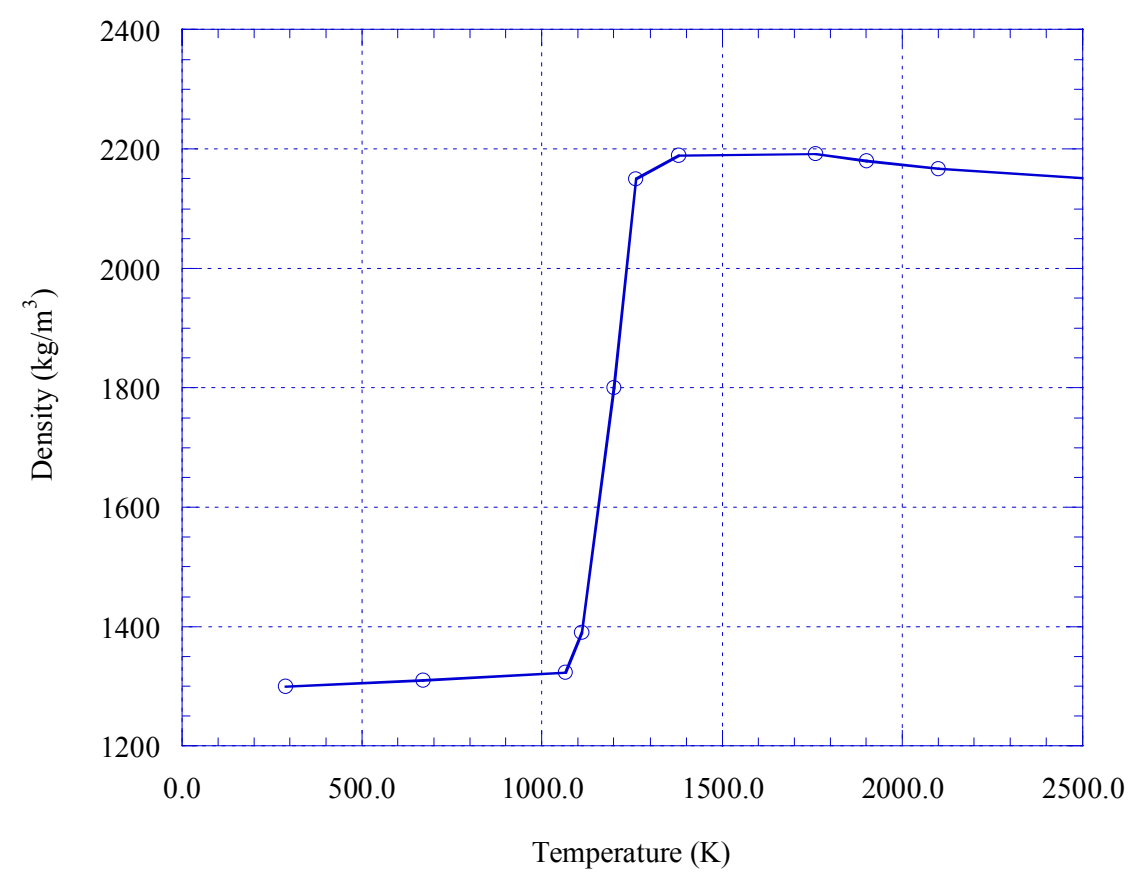

Figure 4. Density versus temperature for glass frit.

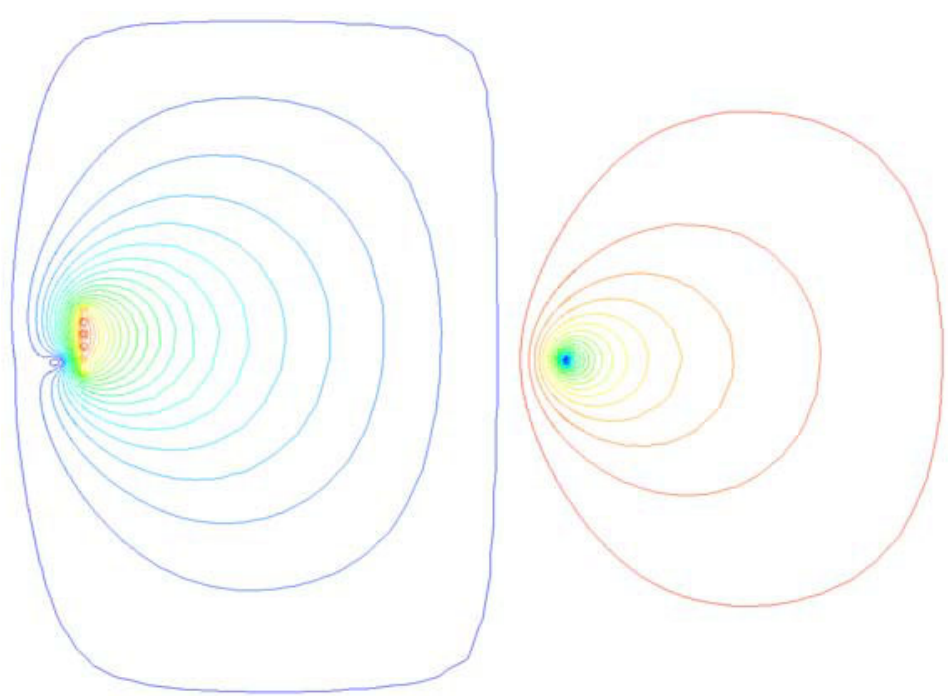

Figures 6 and 7. Imaginary and real magnetic vector potential contours plots, respectively. Imaginary minimum is $-3.89 \mathrm{e}-5$ and maximum is $2.08 \mathrm{e}-3$. Real minimum is $-3.07 \mathrm{e}-4$ and maximum is 0.0 . Units are $\mathrm{m}-\mathrm{T}$. 


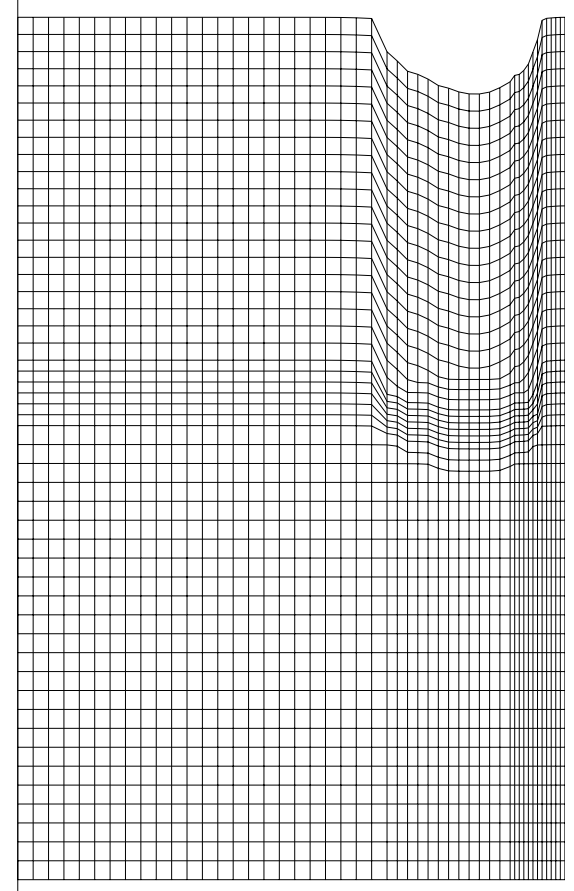

Figure 8. Deformed finite element mesh of glass frit at 100 seconds.

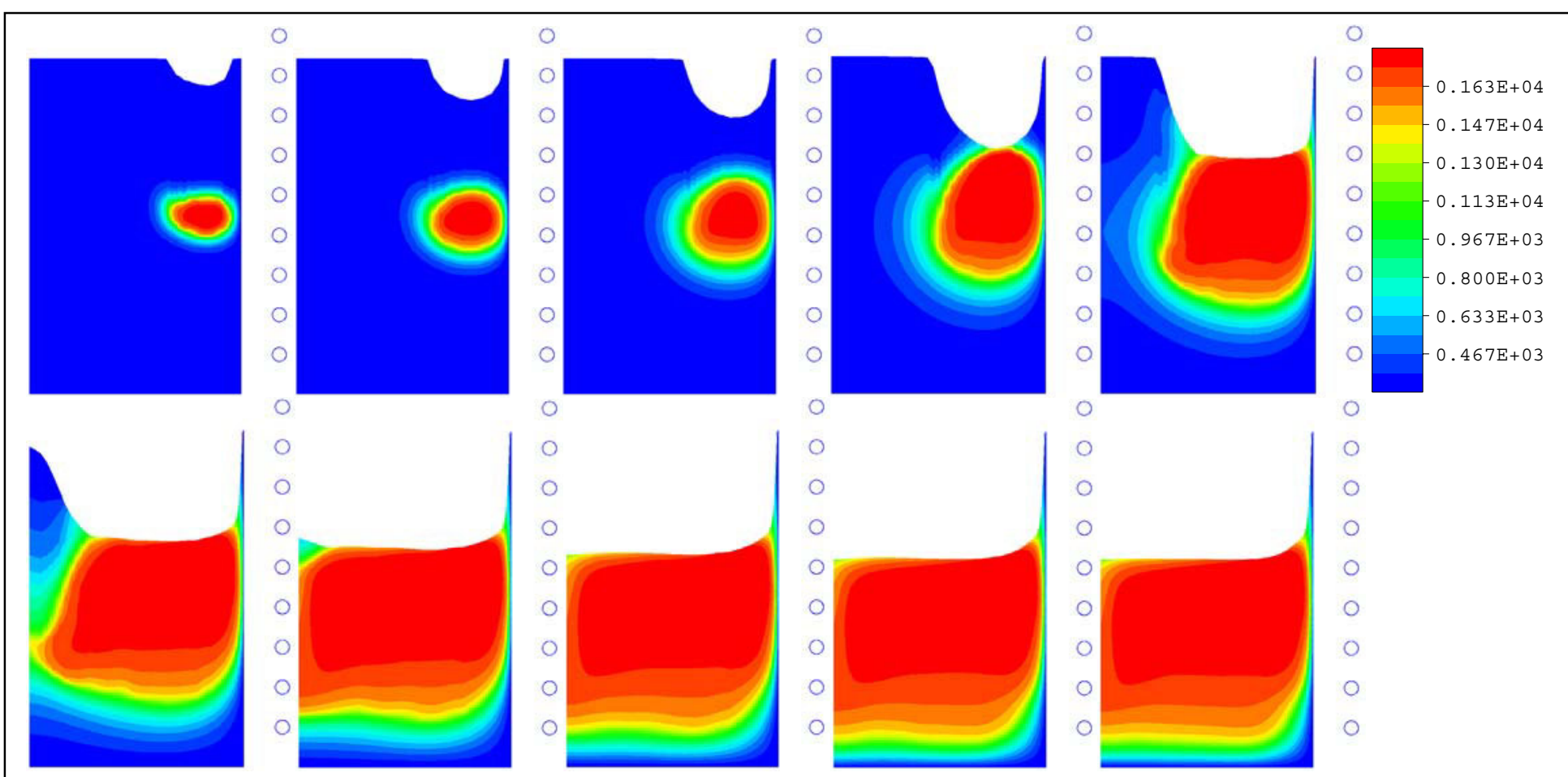

Figure 9. Temperature contours at 100, 200, 400, 800, 1200, 1600, 2000, 2400, 3000, and 3600 seconds. Red is $1800 \mathrm{~K}$, blue is $290 \mathrm{~K}$. 


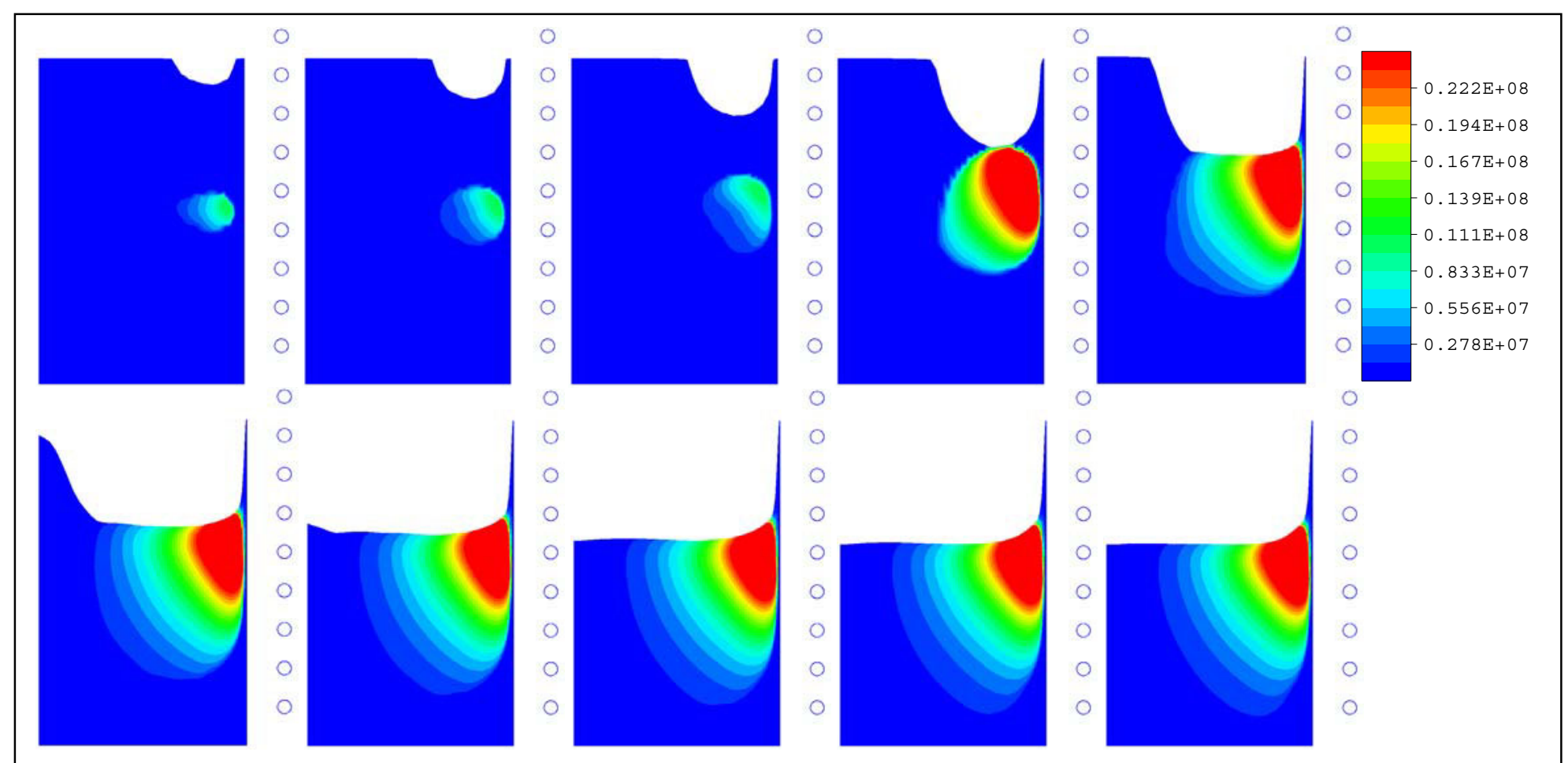

Figure 10. Heat generation rate contours at $100,200,400,800,1200,1600,2000,2400,3000$, and 3600 seconds. Red is $25 \mathrm{e} 6 \mathrm{~W} / \mathrm{m}^{3}$.

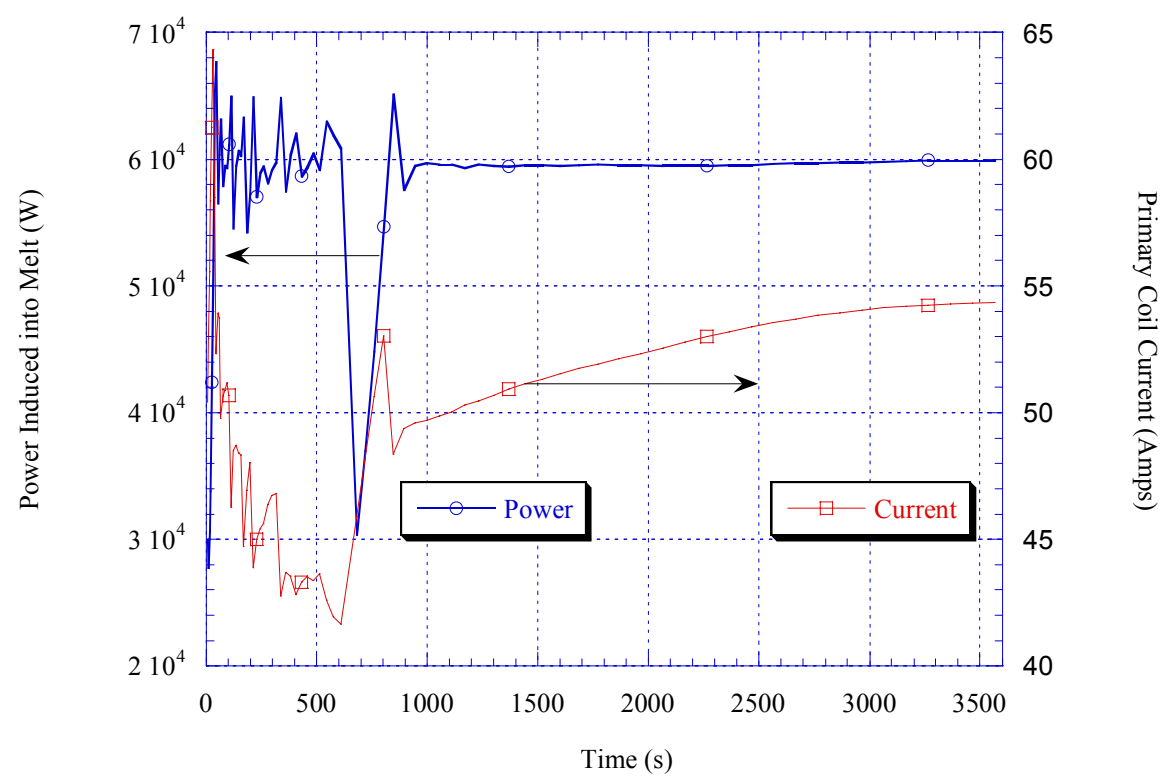

Figure 11. History of induced power into melt and primary coil current. 

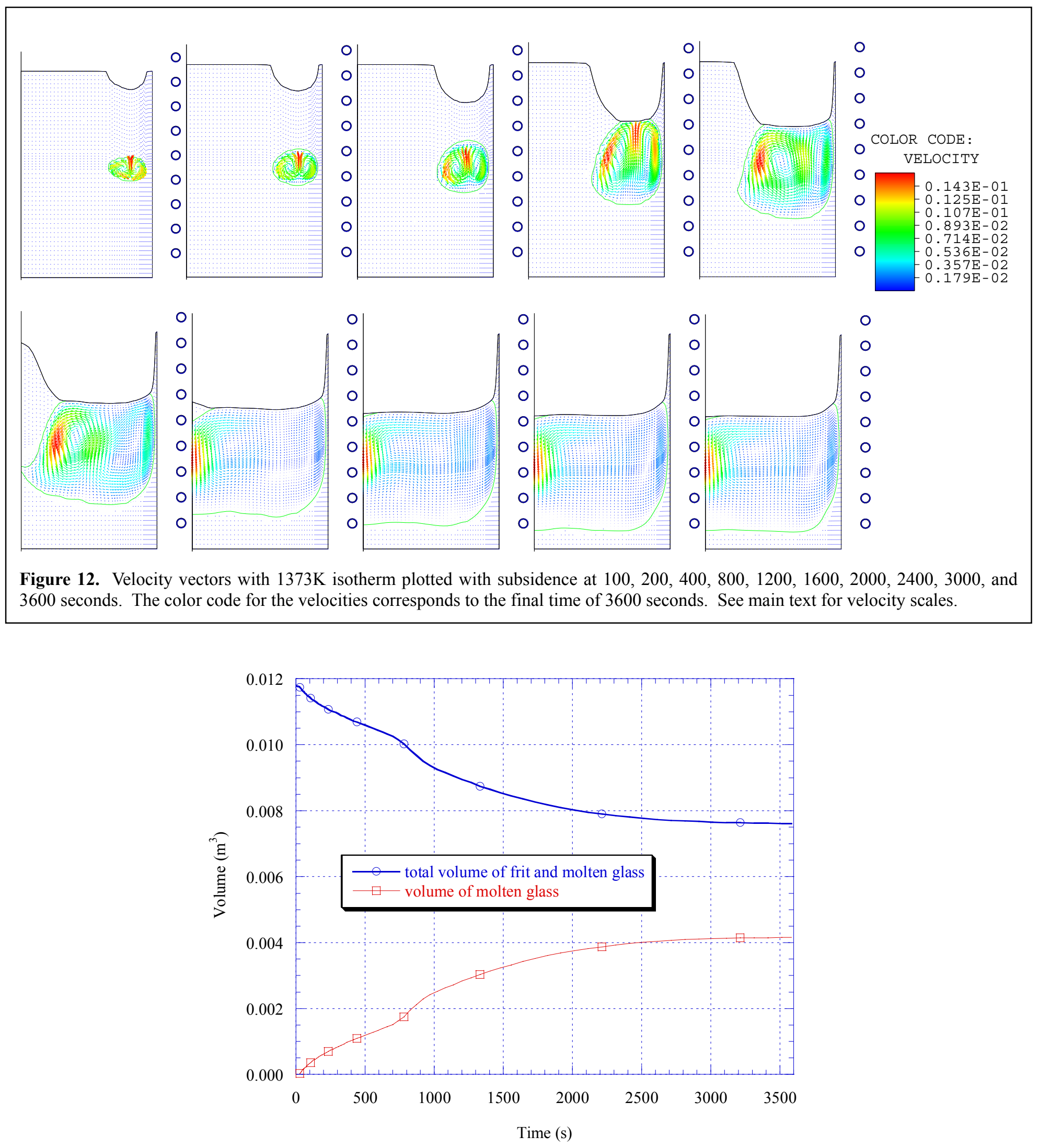

Figure 13. History of frit and molten glass volumes. 